\title{
Experiencias y sentires en torno a la pandemia del virus COVID-19, la perspectiva de los estudiantes universitarios
}

\author{
Dra. Felisa Yaerim López-Botello \\ felisa.lopez@seiem.edu.mx \\ Universidad Pedagógica Nacional 151, Toluca, México \\ Universidad Autónoma del Estado de México, México \\ https://orcid.org/0000-0003-1732-4979
}

\author{
Dra. Araceli Mendieta-Ramírez \\ araceli.mendieta@seiem.edu.mx \\ Universidad Pedagógica Nacional 151, Toluca, México \\ https://orcid.org/0000-0002-4507-237X

\section{Dr. Saúl Alejandro-García} \\ saul.alejandro@seiem.edu.mx \\ Universidad Pedagógica Nacional 151. Toluca, México \\ https://orcid.org/0000-0002-5707-3601.
}

Recepción:15 de febrero del 2021

Aprobación:13 de abril del 2021

Publicación: 06 de junio del 2021

\section{Resumen}

Este artículo constituye un ejercicio de reflexión sobre los efectos de la educación a distancia en estudiantes de Instituciones de Educación Superior (IES), ante la emergencia sanitaria provocada por la pandemia del virus COVID-19, que ha tenido efectos en los ámbitos social, económico, familiar y personal.

Los ajustes y adaptaciones a los recursos digitales han significado diversos grados de dificultad, en función de su combinación o cruce con las brechas regionales, económicas, digitales, desigualdades y desventajas que se podrían seguir desagregando, como la alfabetización digital, tanto para docentes y estudiantes. Estas miradas a las desigualdades ponen al descubierto las realidades locales, familiares y personales de los estudiantes conectados y desconectados de la educación digital.

En este escenario de tránsito repentino de la educación presencial a la educación digital, la presente investigación se realizó con el objetivo de explorar las experiencias y sentires de los estudiantes de dos universidades públicas, para ampliar la información sobre las formas en que 
se adaptaron durante el periodo de confinamiento a las condiciones de inmovilidad y educación a distancia, así como los recursos digitales que utilizaron.

Se inició con una genealogía sobre las bases y principios en los que se funda las transformaciones que problematizan el papel de la universidad pública latinoamericana. Seguidamente, se reflexionó sobre el papel que han tomado la Universidad Pedagógica Nacional (UPN), 151 Toluca y la Universidad Autónoma del Estado de México (UAEMex), en relación con la emergencia, a través de un diagnóstico socioeducativo. La importancia de conocer las experiencias de estudiantes permitió integrar la preocupación por el estado anímico al tema de las desigualdades digitales y entornos locales. El estudio identificó que los estudiantes de la Universidad Autónoma de México presentaron ciertos temores relacionados con problemas de conectividad, salud y economía. Mientras tanto, los estudiantes de la UPN mostraron preocupaciones en torno a la economía familiar, la salud y la conectividad, pero a diferencia de los primeros, los estudiantes Upnianos son más vulnerables por el contexto geográfico-social en donde viven.

También el estudio permitió la reflexión de que se requiere flexibilizar el currículo, como mencionan los expertos, uso de las plataformas en función de las necesidades de cada asignatura. Se insiste en que la educación tiene que ser flexible y adaptarse a las necesidades y características de los estudiantes y de los diversos contextos sociales y culturales. Esto exige, transitar desde una pedagogía de la homogeneidad hacia una pedagogía de la diversidad, aprovechando ésta como una oportunidad para enriquecer los procesos de enseñanza, aprendizaje y optimizar el desarrollo personal y social.

Palabras clave: Universidad pública, COVID-19, educación digital, sentires, desigualdad socioeducativa. 


\title{
Experiences and feelings around the COVID -19 pandemic, the perspective of college students
}

\begin{abstract}
This article constitutes an exercise in reflection on the effects of distance education on students of Higher Education Institutions (IES), given the health emergency caused by the COVID-19 virus pandemic, which has had effects in the social and economic spheres, family and personal.
\end{abstract}

Adjustments and adaptations to digital resources have meant varying degrees of difficulty, depending on their combination or intersection with regional, economic, digital gaps, inequalities and disadvantages that could continue to be disaggregated, such as digital literacy, for both teachers and students. These views of inequalities reveal the local, family and personal realities of students connected and disconnected from digital education.

In this scenario of sudden transition from face-to-face education to digital education, this research was carried out with the aim of exploring the experiences and feelings of students from two public universities, to expand the information on the ways in which they adapted during the period of confinement to the conditions of immobility and distance education, as well as the digital resources they used.

It began with a genealogy on the bases and principles on which the transformations that problematize the role of the Latin American public university are based. Next, they reflected on the role that the National Pedagogical University (UPN), 151 Toluca and the Autonomous University of the State of Mexico (UAEMex) have taken in relation to the emergency, through a socio-educational diagnosis. The importance of knowing the experiences of students allowed us to integrate the concern for the state of mind to the issue of digital inequalities and local environments. The study identified that the students of the Autonomous University of Mexico, presented certain fears related to problems of connectivity, health and economy. Meanwhile, UPN students showed concerns about the family economy, health and connectivity, but unlike the former, UPN students are more vulnerable due to the geographical-social context in which they live.

The study also allowed the reflection that it is necessary to make the curriculum more flexible, as the experts mention, the use of platforms according to the needs of each subject. It insists that education has to be flexible and adapt to the needs and characteristics of the students and 
the various social and cultural contexts. This requires moving from a pedagogy of homogeneity to a pedagogy of diversity, taking advantage of this as an opportunity to enrich the teaching and learning processes and optimize personal and social development.

Keywords: Public university, COVID-19, digital education, feelings, socio-educational inequality.

\section{Introducción}

En México, como en el resto de América Latina, los cambios en el sistema universitario han implicado la transnacionalización de la educación superior y el interés desmedido por la formación técnica, la mercantilización del conocimiento, el aseguramiento de la calidad y la acreditación (Didou, 2002). Este conjunto de intereses afecta la formación académica basada en valores, el desarrollo de la capacidad reflexiva, crítica e innovadora y el interés por la sociedad para contribuir a resolver sus problemas comunes.

En el caso de las Instituciones de Educación Superior (IES) públicas, se han caracterizado por ser espacios constructores de pensamiento, innovación para el bien común, capaces de conjugar las utopías de personas de distintas clases socioeconómicas.

Desde aquellos para quienes los estudios superiores constituyen el camino natural a seguir, hasta quienes abren trecho a posibilidades que no existían en los imaginarios de su inmediatez, los valores del conocimiento y la formación académica como camino para construir una mejor sociedad (y condiciones de vida más dignas), plantean en el ingreso a la universidad un horizonte lleno de esperanza y de realización. Todo esto, dota de sentido a la inversión de fondos públicos en la educación que han sido mermados y que se encuentran en constante amenaza por parte de las y los detractores de este modelo educativo, que persigue la universalidad e inclusividad.

México se ha caracterizado por ser un país diverso y esta característica ha sido más evidente que nunca durante el confinamiento por COVID-19, momento en el que la desigualdad regional, económica, social y cultural se manifiesta en el ámbito educativo.

En México se instruyó a los docentes de todos los niveles escolares para que se dispusieran a impartir clases a distancia a sus alumnos. Dicha instrucción se estableció en el acuerdo 02/03/20, presentado por el secretario de la SEP, Esteban Moctezuma Barragán, publicado el 
16 de marzo de 2020, en el que se dio a conocer la suspensión de clases en las escuelas de educación preescolar, primaria, secundaria, normal y demás, para la formación de maestros de educación básica del Sistema Educativo Nacional, así como aquéllas de los tipos medio superior y superior dependientes de la SEP (DOF 2020, p. 1). Sin embargo, en el acuerdo presentado no se dieron recomendaciones puntuales, ni un soporte técnico o metodológico por parte de la Secretaría para llevar a cabo la instrucción, además de que la educación a distancia se consideró bajo el supuesto de que se contaba con el equipo necesario para una generación de nativos digitales y conectividad.

A los vacíos instruccionales habría que agregar la estimación de acceso a equipos y conectividad, de acuerdo con datos del Instituto Nacional de Estadística y Geografía (INEGI), en su Encuesta Nacional sobre Disponibilidad y Uso de Tecnologías de la Información en los Hogares en 2019, sólo alrededor del $40 \%$ de los hogares en México cuentan con una computadora. Esto representa un problema de brecha de desigualdad tecnológica y advierte que, al no proveer a los estudiantes de las herramientas necesarias, el gobierno mexicano está incumpliendo con el derecho a la educación y bajo esta condición, la falta de conectividad puede ser considerada un elemento de costo que le quite el sentido de gratuidad a la escuela pública.

De ahí que el propósito de la presente investigación sea reflexionar sobre los efectos de la educación a distancia en estudiantes de Instituciones de Educación Superior (IES) ante la emergencia sanitaria provocada por la pandemia del virus COVID-19, a través de la recuperación de experiencias de cómo los estudiantes de nivel superior han vivido la pandemia. Lo anterior permitió ver los recursos desiguales de los estudiantes y docentes, que no sólo tienen que ver con equipo y conectividad, sino también con habilidades digitales y humanismo digital, por ser un importante impacto en la educación superior, ya que su uso, débil uso o mal uso integra sistemas (materiales y simbólicos), agentes y prácticas culturales, interacciones y comunicaciones para fortalecer los mecanismos de inclusión, además que le da una perspectiva académica, orientada a la generación y divulgación de conocimiento.

Otros factores resultados del diagnóstico fueron los cambios de uso de espacios para los estudiantes en sistemas cerrados, las prácticas pedagógicas que privilegiaron el individualismo y no apoyaron el trabajo colaborativo entre los estudiantes, el surgimiento de nuevas 
necesidades y desigualdades, la administración del tiempo y la adaptación del espacio privado; condiciones que afectan el estado anímico de estudiantes.

\section{Desarrollo}

La Organización de Estados Iberoamericanos establece el marco de calidad de educación para todos desde un enfoque de derechos humanos, enfatizando que la pertinencia de la educación alude a la necesidad de que ésta sea significativa para personas de distintos estratos sociales y culturas así como, con diferentes capacidades e intereses de forma que puedan apropiarse de los contenidos de la cultura mundial y local, y al mismo tiempo, construirse como sujetos desarrollando su autonomía, autogobierno y su propia identidad.

De acuerdo con el análisis de impactos, respuestas políticas y recomendaciones de la Organización de las Naciones Unidas para la Educación, la Ciencia y la Cultura (UNESCO) y del Instituto Internacional de la UNESCO para la Educación Superior en América Latina y el Caribe (IESALC) realizado en mayo de 2020, de la noche a la mañana, las escuelas y universidades de todo el mundo cerraron sus puertas afectando a 1.570 millones de estudiantes en 191 países. Esta situación sin precedentes tiene consecuencias en cascada en las vidas de los estudiantes, tanto si están cursando estudios en el extranjero como en su propio país.

Las estimaciones de la UNESCO, IESALC para marzo 2020 muestran que el cierre temporal afectó aproximadamente a unos 23,4 millones de estudiantes de educación superior y a 1,4 millones de docentes en América Latina y el Caribe; esto representó, aproximadamente, más del $98 \%$ de la población de estudiantes y profesores de educación superior de la región.

En la perspectiva de Ángel Díaz Barriga, en el caso de México, las medidas de educación básica, la "Nueva escuela mexicana digital, Desaprendiendo para aprender", abrió la puerta de la educación a gerentes de Google for Education y profundizó la desigualdad, igual que en educación media superior y superior (Alcántara, 2020; Barriga, 2020; Barrón, 2020; De la Cruz, 2020; Ducoing, 2020).

La modalidad de educación a distancia no sólo tiene que ver con el ajuste del tiempo y la adaptación del espacio privado, sino también con un modo de pensamiento capitalista y neoliberal que promueve el individualismo y deja a un lado el trabajo colaborativo (Plá, 2020; Torres, 2020), hechos que provocan formas cada vez más aisladas de aprender, que no se basan en escenarios reales, sino en supuestos. En la perspectiva de Sebastián Plá, la escuela no se ha 
adaptado a la sociedad, sino la sociedad a la escuela y para revertir este escenario se tendría que insistir en educar para el trabajo colectivo y no competitivo (Plá, 2020).

El uso de las tecnologías digitales para los docentes ha ocurrido en medio de un bombardeo de cursos de capacitación para el uso de las plataformas digitales. La mayoría está poniendo a prueba su imaginación y disposición para preparar clases, asesorías, ejercicios, consultorías, evaluaciones, reuniones, conversatorios o webinars a partir de los recursos con los que cuenta; al respecto, especialistas en el tema como la Dra. Ana María Berruecos Vila, Directora de Enseñanza y Aprendizaje Mediados por las Tecnologías (DEAMeT) (Ibero, 2020), de la Universidad Iberoamericana de la Ciudad de México y Ángel Díaz Barriga (2020), señalan que la educación en línea requiere de un gran trabajo previo, tanto de diseño institucional como de contenidos, que involucra a un equipo de expertos de diversas áreas disciplinares como: pedagogos, psicólogos educativos, especialistas en software, diseñadores interactivos y gráficos entre otros, quienes conjuntan sus conocimientos para lograr ambientes de aprendizaje virtuales, que motiven a que la experiencia educativa en línea sea realmente significativa para los estudiantes.

La educación a distancia implica nuevas formas de interacción, que consisten en la adaptación del tiempo y el espacio escolar, al tiempo y espacio privado. No sólo se trata de procesos didácticos distintos de clases, chats, foros, recursos gráficos, entre otros, y el funcionamiento de la red diferente, hay horarios de saturación que obligan a docentes y a estudiantes a cambiar la distribución del tiempo frente al monitor y a innovar e incluso improvisar formas de evaluación. En esta línea de discusión Lourdes M. Chehaibar, considera que estas condiciones llevan hacia una práctica sesgada y poco pedagógica del sentido de educar (Chehaibar, 2020). Con toda la cantidad de recursos y opciones que las plataformas de eLearning puedan tener, aún no se llega a acceder a ellas en su totalidad, por las desigualdades referidas. Una diferencia contrastante con la IES privadas no sólo es que llevan ventaja en el uso de plataformas digitales, sino que además existen desventajas de todo tipo entre los estudiantes de las IES públicas, porque en los lugares donde hay menos cobertura de servicios de internet, también hay más variación con respecto a las condiciones de infraestructura, por el uso compartido del espacio físico y el tiempo para estudiar, que tienen efectos en los aprendizajes. La recuperación de experiencias expuso que estas desigualdades se manifiestan en estados emocionales, como estrés y preocupación. 
La virtualización de la enseñanza no sólo ha reducido la movilidad de los estudiantes y el cambio de uso de los espacios para socializar y construir comunidad (Chehaibar, 2020) sino también para fortalecer su sentido de pertenencia. Las tecnologías educativas no logran sustituir las clases presenciales, porque han invadido la privacidad del hogar, transformado las formas de interacción, de construcción colectiva y cognitiva, además de la convivencia, de circulación de las ideas, de los pensares y sentires colectivos.

El paso a la educación remota o virtual implica fomentar la lógica de mercado, en la que se privilegia el individualismo y la competencia, además de que los estudiantes pierden un espacio vital (escuela) para canalizar sus energías y sus emociones.

Es por eso que la escuela pública ha sido quizá un lugar clave para posibilitar la circulación de ideas y el encuentro de la diversidad (Dietz, 2020, 2021), para analizar las experiencias y sentires en torno a la pandemia del virus COVID-19 en los que se refiere al confinamiento, inmovilidad, aislamiento, a la educación remota y al distanciamiento físico que se confunde con distanciamiento social, que hace referencia la polarización social (Torres, 2020). En este sentido, la inmovilidad y aislamiento empujan a los estudiantes al individualismo y a problemas emocionales, en ambos escenarios, las plataformas virtuales no favorecen la construcción, tampoco el fortalecimiento de lazos sociales, ni el reconocimiento de la diversidad (Chehaibar, 2020), o el sentido de pertenencia.

La presión que implica el desempeño en ambientes virtuales, la incertidumbre laboral, los efectos de la pandemia en la salud, la convivencia de la familia, los límites de la expresión y la comunicación, así como la doble hermenéutica de los medios de comunicación, fomentan miedo, incertidumbre y problemas relacionados con el ámbito emocional (Alcántara, 2020); una vía que Lourdes $M$. Chehaibar identifica para solucionar algunas tensiones es la flexibilidad del currículo:

...pensar de otra forma el sentido de educar y el currículo; para diseñar políticas públicas que nos permitan atender la desigualdad, así como la violencia de género, que son visibilizadas en el contexto de la cuarentena; para analizar el rol del profesor y nuestra concepción del aprendizaje como praxis, como relación dialéctica; para repensar las estrategias didácticas orientadas a una verdadera formación de estudiantes; para prever rutas diversificadas y nuevas destrezas que promuevan el acto de aprender; para dudar de principios que creíamos 
inamovibles y que, hoy pueden limitar creaciones utópicas, arriesgadas y creativas en beneficio de las mayorías (Chehaibar, 2020, p. 88).

La reflexión de Lourdes M. Chehaibar (2020) es compartida por Gabriela de la Cruz Flores, quien también identifica que algunos hogares no sólo son afectados por las desventajas de no contar con tecnología y conectividad, sino que además viven problemas de violencia intrafamiliar y que difícilmente los estudiantes podrían tener condiciones para el estudio (De la Cruz, 2020).

En esta línea de discusión Gunther Dietz y Laura Selene Mateos Cortés, también plantean la relevancia de pensar desde la diversidad sin perder de vista la desigualdad en la experiencia de educación a distancia, para que “... en vez de prometer normalidad a toda costa, el entrante año escolar 2020-2021 debería convertirse en el momento inaugural de todo un proceso de experimentación e innovación educativa desde abajo...” (Dietz \& Mateos, 2020, p. 41).

El confinamiento, como medida para contener la pandemia por COVID-19, propició un despliegue acelerado de soluciones de educación a distancia para asegurar la continuidad pedagógica, con múltiples obstáculos, como la falta de conectividad, TIC para acceder a la educación digital, falta de contenido en línea ajustado a los planes de estudio nacionales, profesorado no preparado para la nueva normalidad. En el caso de los docentes, tuvieron que hacer uso de diversas plataformas virtuales, con las que no están familiarizados (Alcántara, 2020; Barrón, 2020; Ducoing, 2020), en términos de María Concepción Barrón:

Las TIC, por sí solas, no tienen una función pedagógica y su uso no siempre conlleva procesos pedagógicos innovadores. Si bien es cierto que la introducción de las tecnologías en la educación ha generado prácticas innovadoras como la gamificación de la enseñanza, el technocraft (aprendizaje de la programación), el big data o el mobile learning, no siempre ha sido el motor de cambio en la escuela y sí un elemento didáctico más que no llega a modificar de fondo las prácticas educativas... Esta coyuntura compleja debe contribuir, pues, a cambiar las formas en las que enseñamos y aprendemos; no sólo sumar la tecnología a los procesos educativos, sino que realmente sea una disrupción que cambios profundos en las prácticas pedagógicas cotidianas (Barrón, 2020, p. 70).

Esto propició que los docentes debieran estar inscritos en diversos cursos, talleres, diplomados y certificaciones de empresas trasnacionales y nacionales ajenas a lo pedagógico, cumpliendo con las metas que la SEP planteó para atender la atención educativa. 
El encuentro entre la educación presencial y la educación digital, no sólo fue motivado por la prevención de la pandemia por COVID-19 para reducir el contagio, sino por el panóptico de las autoridades educativas para no perder el año escolar (Chehaibar, 2020), condiciones que han inducido a 400 mil docentes y más de 4 millones de estudiantes de licenciatura y posgrado, en las IES del país (López \& Rodríguez, 2020, p. 103), a prácticas educativas a través de recursos digitales.

En cuanto a los estudiantes, una de las lecciones aprendidas de la pandemia por COVID-19, fue que las condiciones de desigualdad de las IES públicas en comparación con las privadas son las más vulnerables y las que más oportunidades de aprendizaje han perdido con la educación digital, sobre todo en áreas rurales, tal y como expresa Armando Alcántara:

La pandemia ha mostrado, nuevamente, que los estudiantes de los grupos más vulnerables han sido los más afectados...lograr equidad en la educación superior para los grupos vulnerables de la sociedad sigue siendo uno de los mayores desafíos (Alcántara, 2020, pp. 78-80).

En el caso de México, la desigualdad regional implica que existe una brecha digital localizada geográficamente, que además se cruza con otras desigualdades sociales, económicas y culturales, que se profundizan con la pandemia COVID-19 (Alcántara, 2020; Barrón, 2020; Chehaibar, 2020; Ducoing, 2020), como explica Patricia Ducoing Watty:

...los hogares más desfavorecidos con respecto al acceso a internet son de entidades como Chiapas, Oaxaca, Tlaxcala, Guerrero y Veracruz, mientras que Sonora, Baja California Sur, Quintana Roo, Baja California y Nuevo León representan las entidades federativas con mayor conexión a internet... El costo educativo de esta inédita situación para los sectores sociales más vulnerables es mucho mayor que para los grupos más desfavorecidos (Ducoing, 2020, pp. 57-63).

Con respecto a los casos auténticos de la UPN y la UAEMex, se observó que los estudiantes provenientes de zonas rurales experimentaron situaciones más precarizadas, por ejemplo, sólo el $47 \%$ de los encuestados de la UPN contaba con servicio de internet en sus localidades, mientras en el caso de la UAEMex el servicio de internet alcanzó al 78.7 \% de los encuestados. En cuestión anímica, las familias de estudiantes de la UPN sólo 30\% expusieron condiciones favorables. Mientras para las familias de los estudiantes de la UAEMex, el $80 \%$ de los encuestados señaló contar con un ambiente familiar favorable. 
Respecto a las aplicaciones más utilizadas por los estudiantes de la UPN en sus clases virtuales, fue el uso polarizado de diferentes recursos digitales a diferencia que los estudiantes de la UAEMex, recurrieron a plataformas como SEDUCA, TEAMS, Schology, Classroom, y Moodle.

En las apreciaciones sobre las respuestas educativas a la emergencia sanitaria, los líderes de las universidades de América Latina estimaron que las clases digitales, las necesidades tecnológicas y las habilidades diferenciales están relacionadas con las emociones y es fundamental considerar el estado anímico de estudiantes y profesores (BID, 2020).

En medio de la discusión ética ante los posicionamientos por las catástrofes ocasionadas por la pandemia y la crisis, la entrada al periodo de emergencia y al confinamiento, ha significado el paso de la movilidad, espacios comunes, convivencia, flujo de ideas y socialización de los aprendizajes y experiencias compartidas a un repentino proceso de educación a distancia, caracterizado por la inmovilidad, la pérdida de espacios comunes y la reafirmación de las desigualdades: primero entre conectados y desconectados; y después, a una desigualdad de habilidades digitales y a la falta de espacios propicios para el estudio.

\section{Metodología}

A partir de la pandemia por COVID-19, el 23 de marzo de 2020, la investigación remota, vía on-line cobra importancia ante las restricciones de movilidad y el riesgo que implica la investigación face to face, razón por la cual, resultó estratégica la utilización de instrumentos digitales que permitieron realizar la presente exploración a partir de un diagnóstico socioeducativo.

La recuperación de experiencias y sentires de los universitarios de las IES públicas en el Estado de México, fue de carácter cualitativo, haciendo uso de la técnica de la encuesta, a través del instrumento del cuestionario con preguntas abiertas y cerradas durante un periodo de mayo a julio 2020, con una muestra intencionada de 90 estudiantes de la Universidad Pedagógica Nacional, Unidad 151 (Toluca y Sede regional Ixtlahuaca) y una muestra de 94 estudiantes de la Universidad Autónoma del Estado de México (UAEMex), procedentes de las Facultades de Ciencias de la Conducta, Antropología, Contaduría y Administración.

El instrumento se dividió en cuatro ámbitos de interés: local, institucional, familiar y personal, para conocer el acceso que tienen a la tecnología, la conectividad, las ventajas y desventajas 
de las clases remotas, así como su estado anímico a partir del confinamiento. En este orden de ideas, el objetivo de la presente investigación fue explorar las experiencias y sentires de los estudiantes de dos universidades públicas, ampliando la información sobre las formas en que se ajustaron a las condiciones de inmovilidad y educación a distancia, así como los recursos digitales que utilizaron.

\section{Resultados}

\section{Diagnóstico socioeducativo}

En la exploración de las realidades de los estudiantes de la UPN, Unidad 151 y la UAEMex, la información se presentó a través de cuatro dimensiones de análisis: el contexto local y familiar, el ámbito de las instituciones educativas, las experiencias y aprendizajes, los sentires de los estudiantes frente a los desafíos digitales y las perspectivas que tienen sobre el futuro. Los estudiantes de la UPN, Unidad 151, proceden principalmente de municipios del Valle de Toluca - Ixtlahuaca: Toluca, Ixtlahuaca, Jiquipilco, Jocotitlán, Villa del Carbón, Atlacomulco, San Felipe del Progreso, Almoloya de Juárez, Zinacantepec, Morelos, Jocotitlán y San Mateo Atenco. Y los de la UAEMex son de Toluca, Zinacantepec, Metepec, San Mateo Atenco, Ocoyoacac, Lerma, Almoloya de Juárez, Ixtlahuaca, Capulhuac, Morelos, Temoaya, Tejupilco e Ixtapan de la Sal.

De los 90 estudiantes de la UPN 151, el $42 \%$ de los encuestados tiene entre 18 y 20 años, $36 \%$ tiene entre 21 y 22 años y el $21 \%$ es mayor de 23. De los 94 de la UAEMex, el $48 \%$ tiene una edad entre 18 a 20 años, $38 \%$ entre 21 y 22 años, así como $14 \%$ más de 23 años. Mientras en la UPN la muestra corresponde a $79 \%$ que son mujeres y el $21 \%$ son hombres, en la muestra de la UAEMex las mujeres constituyeron el $74 \%$ y $25 \%$ son hombres.

Entre las características de los contextos locales de los estudiantes que integraron la muestra de la UPN, sólo el $47 \%$ cuenta con servicio de internet en sus localidades, mientras en el caso de la UAEMex el servicio de internet alcanza el 78.7\%.

Entre las actividades que los estudiantes de la UPN identificaron con más cambios, se mencionan en primer lugar las económicas por la disminución y/o pérdida del empleo, del ingreso familiar, los despidos sin liquidación, el cierre de negocios locales, la ausencia de vendedores callejeros, la imposibilidad de que todas las personas se queden en sus casas porque tenían que buscar formas de proveer a sus familias a pesar del riesgo y la limitación de 
alimentos para el consumo familiar. Entre sus principales preocupaciones, señalaron el paro de actividades recreativas y religiosas, pero también les inquietó que las personas no creían en el virus, las salidas sin precaución y la posibilidad de que se elevara el riesgo de contagio para todos.

En cuanto a los estudiantes de la UAEMex, los cambios que más les impactaron durante la cuarentena fueron: negocios cerrados, despidos de trabajos, pocas entradas económicas en algunas familias, trabajo en casa y en otras, hubo quienes señalaron conflictos familiares, el cierre o la poca actividad de centros de recreación como parques, las iglesias, gimnasios, cines, entre otros.

Con respecto a los cambios que los estudiantes de la UPN realizaron a nivel familiar destacó, la adaptación al uso de las tecnologías y redes sociales, para comunicarse y poder desempeñar sus labores en los horarios de trabajos escolares. En el nivel familiar de los estudiantes de la UAEMex, los cambios más significativos tuvieron que ver con la presión de las clases en línea, pasaron más tiempo frente al teléfono móvil y la computadora; otros durmieron la mayor parte del tiempo y pasaron momentos de aburrimiento, ocio y en algunos se integraron a actividades cotidianas, como los quehaceres de la casa, y en algunos casos los estudiantes tuvieron que salir a trabajar para apoyar a su familia con ingreso económico.

El estado de ánimo en las familias de estudiantes de la UPN sólo fue favorable para el 30\% y desfavorable para el 70\%. Mientras en el ámbito familiar de los estudiantes de la UAEMex, sólo el $20 \%$ señaló conflictos fuertes en casa, el $30 \%$ se mostró indiferente al cambio y el 50 $\%$ de las familias se sintió cómoda. Estas reacciones diferenciadas al confinamiento desestabilizan principalmente a familias, de estudiantes de la UPN, quienes expresaron: miedo, aburrimiento, estrés, tristeza, confusión, depresión, desesperación, frustración, angustia, preocupación, agotamiento, incertidumbre, irritabilidad, tensión y enojo.

Es importante mencionar que antes de la pandemia, algunos jóvenes pasaban más tiempo en la escuela, con sus amigos y normalmente los fines de semana apoyaban a sus familiares. Con la pandemia, se observan más casos de estudiantes de la UPN con necesidad de aportar al ingreso familiar y los estudiantes de la UAEMex, predominantemente en confinamiento se relacionaron más con su familia y en sus tiempos de "ocio" se "entretuvieron" en las redes sociales, viendo algunas películas o series de plataformas como "Netflix", en el celular y en el WhatsApp o bien realizaron arreglos en la casa. 
Es importante mencionar que sólo el $53 \%$ de la muestra de estudiantes de la UPN cuenta con internet en casa, el $43 \%$ usa datos y $3 \%$ va a un ciber a hacer sus tareas y a tomar clase. Dentro del porcentaje que tiene internet en casa, el $71 \%$ no cuenta con equipos suficientes para que toda la familia tome clases o trabaje en línea. En tanto los estudiantes de la UAEMex el $66 \%$ con acceso a internet en casa, $30 \%$ se conecta con datos y solo el $4 \%$ hizo uso del cibercafé. De los jóvenes que tienen internet en casa, el $65 \%$ cuenta con un equipo para toda la familia y el $35 \%$ tiene dos o más equipos.

Respecto a las aplicaciones más utilizadas por los estudiantes de la UPN en sus clases virtuales, fue el uso polarizado, porque más del 80\% utilizó Schoology, WhatsApp, Facebook; 70\% Google Meet y correo electrónico; 26\% recurrió a Zoom; y, las plataformas con un uso menor al 7\% de la muestra fueron Classroom y Skype. Entre los estudiantes de la UAEMex, las plataformas más usadas fueron WhatsApp, Zoom, correos electrónicos y Microsoft Teams con más del 70\%; mientras que entre un $60 \%$ y $40 \%$ utilizaron Facebook, Schoology, Google Meet, SEDUCA y en menor medida Classroom y Moodle con porcentajes menores al $40 \%$. El uso de las plataformas fue más variado entre los profesores de la UAEMex porque se les facilitó poner actividades en línea en las plataformas de SEDUCA y Microsoft Teams, porque existe un convenio con esta compañía para el servicio a estudiantes y profesores con cuentas institucionales (por ejemplo, permite instalar el Microsoft 360 y otras paqueterías gratis). Además, la UAEMex previamente al confinamiento desarrolló una plataforma interna, denominada SEDUCA, a cargo de la Dirección de educación continua y a distancia, en la que los profesores comparten materiales, hacen uso de foros, chats, wikis y dejan actividades complementarias al tiempo que trabajan en clase presencial.

En lo referente a los servicios escolares de los estudiantes de la UPN reconocieron como una ventaja la disposición de un correo institucional, así como organización de conversatorios relacionados con educación y pandemia, proporcionándoles información vía WhatsApp; también, en menor medida hubo casos que no sintieron el apoyo de su universidad.

Los estudiantes de la UAEMex sintieron poco respaldo de sus centros de estudios en cuanto a las clases virtuales o en línea, porque muchos maestros no tenían idea de cómo contactar a sus estudiantes, algunos se comunicaron a través del correo personal, otros a través de WhatsApp y Facebook. No existió un consenso institucional por conectarse con los estudiantes. Hubo maestros que aprovecharon el uso de SEDUCA, del correo electrónico, Facebook o el 
WhatsApp para dejar solamente actividades o tareas y esto provocó malestar entre los estudiantes porque solo eran actividades, en ocasiones sin identificar la relación con los temas. La UAEMex tardó en organizarse ante la contingencia y los pocos apoyos otorgados fue una beca en una sola exhibición de $\$ 400.00$, para que algunos estudiantes que no podían conectarse lo hicieran. También se realizaron cursos express, para apoyar a los profesores e invitarlos a usar plataformas como Microsoft Teams, Schoology, Zoom entre otros, con estas herramientas los profesores empezaron a tener más presencia en clases, más allá de las actividades en línea. Con las clases a distancia han podido también hacer una apreciación más profunda de la disposición y flexibilidad de sus maestros, en el caso de los estudiantes de la UPN, sus perspectivas se pueden ubicar entre dos polos: por un lado, los que estuvieron insatisfechos con el uso de recursos digitales y por otro, los que se ajustaron.

Los que estaban insatisfechos mencionaron que en sus casas fue más difícil concentrarse, porque aunado a los problemas de internet, el uso de las plataformas fue complicado, tenían más distractores, sus profesores no les explicaron y no solucionaron sus dudas, tuvieron exceso de tareas y trabajos, que a su vez los hicieron sentirse frustrados, estresados y a partir de esta experiencia valoraron sus clases presenciales. Los estudiantes de la UPN que se ajustaron a la educación digital, reconocieron que tuvieron que aprender a adaptar sus horarios, formas de trabajo y necesidades de las asignaturas, además lograron un mejor manejo de los recursos digitales y pusieron a prueba sus capacidades autodidactas. En este sentido, expresaron satisfacción.

Con respecto a los estudiantes de la UAEMex también existen dos posturas: los que consideran que es regular, porque el trabajo es más pesado que presencial; hay temas importantes que no les explican los docentes, aunque también hay otros que ponen mayor empeño en la impartición en las clases virtuales y dejan tareas significativas, sin llegar a excesos. Manifestaron que hubo profesores que tanto en las clases, como en la relación docente estudiante, no fue adecuada.

Durante el semestre enero - julio 2020, menos de la mitad de los docentes impartió clase continua, se comunicaron a través de correos electrónicos y los demás docentes no les proporcionaron información durante la contingencia. En consecuencia, les resultó pesado el semestre; difícil, tedioso, fastidioso, cansado, aburrido y se vieron obligados a ser autodidactas 
todo el tiempo, incluso, con algunos profesores se tuvo que estar insistiendo para que respondieran los mensajes y dieran indicaciones de clase.

\section{Discusión}

\section{Experiencias y aprendizajes}

En la valoración de ventajas y desventajas que realizaron los estudiantes de la UPN, en orden de frecuencia expusieron una lista de aspectos positivos: mejoró su manejo de las plataformas virtuales, se sintieron sanos y a salvo (no sólo al COVID-19, sino también a accidentes y acoso), ahorraron dinero de los traslados y aprendieron a administrar su tiempo (sobre todo en el caso de los estudiantes que viven lejos de la universidad). En la perspectiva de los estudiantes, cuidan el medio ambiente porque no imprimieron y no consumieron materiales, se volvieron más autodidactas, podían acceder a otros cursos on line, tenían información a la mano (los que contaban con acceso a internet), utilizaron las redes sociales para fines educativos, desarrollaron capacidades para el trabajo colaborativo, sus clases fueron cómodas, siguieron aprendiendo, adquirieron nuevas formas de aprendizaje en conversatorios virtuales, pasaron más tiempo en familia y realizaron trabajos de investigación.

Entre la desventajas expresadas por los estudiantes, las respuestas predominantes fueron en primer lugar, el reconocimiento de que aprendieron en función del interés de cada uno, pero además tuvieron mala conexión, el internet representó un costo extra para los que no tenían el servicio, les faltó equipo adecuado y suficiente (porque compartían equipos con padres, hermanos y otros familiares), salir al ciber representó un riesgo y no había negocios abiertos, las explicaciones fueron poco profundas, estaban saturados de tareas, fue complicado conciliar el trabajo de casa con las clases y tareas, hubo más distractores, había temáticas difíciles de comprender, los que tenían dificultades de conexión se estresaron, las instrucciones que les daban sus profesores no eran precisas, incluso señalaron que algunos docentes no dominaban los temas, tuvieron bajo aprovechamiento y hubo estudiantes que perdieron el interés.

Sobre las razones por las que una parte del grupo no participó en las actividades educativas a distancia, señalaron: la falta de recursos económicos, falta de servicio de internet, defíciente señal, algunos estudiantes no tenían tecnologías de comunicación e incluso enfrentaron problemas familiares y de salud de ellos o de algún miembro de su familia, la distribución del 
tiempo entre sus deberes (algunos son padres o madres), hay quienes tuvieron que salir a trabajar y no conciliaron sus horarios con las clases.

Los aprendizajes de los estudiantes de UPN, no sólo tuvieron que ver con la valoración de las clases presenciales, sino también con la importancia de la sanidad y la prevención, el ahorro, la valoración del tiempo en familia y de la vida, así como el cuidado de sí mismos. Los estudiantes no sólo expresaron su preocupación por el bien individual, sino también por su familia, el entorno social y natural, entre las apreciaciones que representan esa empatía, están las siguientes:

Me hace ser consciente de que la sociedad y un país cambia por uno mismo, lo que haces por alguien lo haces por ti mismo y si tengo la oportunidad de ayudar a alguien lo hago, porque vivimos en una sociedad donde nadie da nada sin recibir algo a cambio, me da coraje el tipo de sociedad en la que vivimos (entrevista on line, 2020).

"Todos somos responsables del bienestar y cuidado de todos" (entrevista on line, 2020).

Siempre he pensado que los más vulnerables son los que sufren más y este tipo de cosas pone esto en evidencia notoria... Considero que después de esto, todos tenemos que ser más solidarios, amables y respetuosos con el resto de la gente que nos rodea. Pero sobre todo recuperar nuestro humanismo, algo que ha quedado bastante olvidado y que hemos cambiado por la envidia o sentimientos negativos como el odio (entrevista on line, 2020).

En cuanto a los aprendizajes relativos a la educación remota de UPN, quizá fueron más los que reconocieron el valor del acceso a la información, la formación autodidacta, la responsabilidad que deben tomar sobre su propio conocimiento, la disposición de los docentes y el valor del intercambio de ideas en las clases presenciales.

Para los estudiantes fue fundamental tanto la disposición de los docentes, como de sus pares, algunos profesores sólo dejaron tareas, no relacionan las tareas con las clases y otros: “... sólo mandan tareas y trabajos y nada de clases virtuales". Los estudiantes de la UAEMex insistieron en que sólo unos pocos docentes se han preocupado por desarrollar un aprendizaje significativo, hubo otros que se conectaron para sus clases, pero no cambiaron sus métodos, tanto didácticos como pedagógicos, en la perspectiva de los estudiantes no sirve: "existen los profes que están cobrando sin hacer nada más que mandar actividades escolares" (entrevista on line, 2020). 
Entre las ventajas que los estudiantes de la UAEMex reconocieron, fue el interés por recuperar sus clases y desarrollar nuevas habilidades tecnológicas, también había casos a los que sólo les importó pasar el semestre. La apreciación general, es que tanto profesores como estudiantes no estaban preparados para resolver este proceso. Es importante decir, que esta exploración proporcionó elementos importantes para repensar las clases a distancia, on line o virtuales. En la valoración de los estudiantes de la UAEMex resaltaron cosas positivas y negativas en torno a las clases, consideraron: no tener que levantarse temprano, ahorro en pasajes, la seguridad de estar en casa, flexibilidad para organizar su tiempo, estudiar en la comodidad, pasar más tiempo en familia y usar nuevas herramientas tecnológicas.

Las desventajas fueron: problemas de concentración, la interacción con el docente no era suficiente para resolver dudas, trabajos complejos, sólo enviaron el PDF, dificultades para organizar su horario, sentían que no aprendían muy bien, excesiva carga de trabajo, no había flexibilidad en la evaluación, no tenían referencias de apoyo. Asimismo, consideraron fundamental la comunicación con los profesores y con sus pares, porque el intercambio y circulación de ideas les permitió aprender más, también valoraron la necesidad de espacios como la biblioteca, aún entre los estudiantes que reconocen su gusto por la tecnología, una frase recurrente fue: “... los maestros creen que dar clases en línea es dejarte un montón de trabajo sin sentido" (entrevista on line, 2020).

\section{Sentires}

Las experiencias con la educación digital entre estudiantes de la UPN, posibilitaron la revaloración de las clases presenciales, que en su perspectiva deberían combinarse con los recursos digitales, para aprovechar ambas opciones, una de las frases que ilustró claramente la apreciación sobre las clases presenciales, fue la siguiente: "las extraño muchísimo y son demasiado necesarias, dicen que valoramos las cosas cuando dejamos de tenerlas y es totalmente cierto. Quisiera regresar a la escuela..." (entrevistas on line, 2020), para algunos las clases virtuales fueron aburridas, tediosas y les hizo falta la interacción física que realizan en la escuela, en las clases presenciales la participación es más activa.

Entre la diversidad de reacciones sobre las clases virtuales, se reconoció la importancia de la modalidad a distancia: 
...soy una persona que se adapta a las circunstancias, creo que eso va más conmigo, me adapté a las clases virtuales porque se requería hacerlo, disfruto estar en mi casa y el hecho de ir a la universidad me agotaba mucho; era estar siempre atenta de poder llegar a casa y ver de nuevo a mi familia. Siempre tenía miedo por lo que me pudiera pasar y me importa más mi seguridad que ir a clases o ver a mis compañeros o maestros (entrevistas on line, 2020).

Hay opiniones que reconocieron un crecimiento personal con las clases virtuales porque complementaron su información con otras fuentes y se hicieron responsables de su aprendizaje.

Entre tanto, los estudiantes de la UAEMex expresaron que a pesar de que les gustan las clases virtuales, la crisis por COVID-19 no les permitió dar lo mejor de ellos y las clases presenciales no deberían intentar transferirse como tal a la virtualidad y viceversa, porque tienen una estructura específica. En oposición a las opiniones de los estudiantes de la UPN plantearon que no son capaces de ser autodidactas y que deberían retarse más en todos los sentidos y valorar lo que tienen. Entre sus aprendizajes, encontraron que con esta experiencia han aprendido a valorar a sus amistades, familia y la escuela, también la vida, el tiempo, las personas y el contacto.

\section{Perspectivas sobre la vida después del confinamiento}

El COVID-19 provocó una sensación de incertidumbre entre los estudiantes de la UPN, Unidad 151, sin embargo, las opiniones pueden ubicarse entre dos extremos, por un lado las opiniones que mantienen cierta esperanza en los cambios que se producirán después del confinamiento, con apreciaciones sobre el cuidado y seriedad con que se tomarán las medidas de prevención sanitaria; consideraron que las relaciones interpersonales ya no serán tan emotivas, ni cercanas; se planteó la posibilidad que exista mayor sensibilidad a estas catástrofes; que la experiencia educativa sea una lección para superar las fallas y desigualdades y una oportunidad para combinar la educación presencial y digital, entre las que se consideran nuevas formas de conocimiento.

En el otro extremo, algunos estudiantes no ven cambios positivos en las conductas colectivas y en la interacción, creen que la gente no aprenderá nada, porque si no se cuidó durante el periodo más riesgoso, menos lo hará después, habrá más indiferencia, desigualdad y 
polarización social, así como carencias en todos los ámbitos, motivo de la crisis económica a escala mundial.

Los estudiantes de la UAEMex manifestaron que la modalidad mixta podría ser efectiva, pero interactuar con compañeros y maestros de forma presencial, es muy importante para aclarar dudas y tener mayor comprensión de los temas, así como experimentar diversas perspectivas, pero con base en ciertas formas de trabajo, es posible que haya más cupo en las escuelas.

Las personas no volverán a ser igual, ni las dinámicas por las medidas de salud que se implementen, suponen que los problemas más graves de superar son los relacionados con las condiciones económicas y no creen que las personas puedan recapacitar, en cuanto a la soberbia y egocentrismo que puso en evidencia la pandemia, la gente se aprovecha de los más desprotegidos o menos informados.

En el ámbito rural, las personas quizá se vuelvan más desconfiadas y no permitan el acceso a su comunidad. Plantean que el tiempo de reflexión no será suficiente, pero es posible que traten de disfrutar más y sacarle provecho a todo, “...sólo espero que toda esa energía dure más de lo que tardemos en volver a acostumbrarnos a la normalidad" (entrevista on line, 2020).

\section{Conclusiones}

Es importante considerar que la educación digital no es un reemplazo de las clases presenciales, sino es una respuesta al confinamiento por COVID-19; y las experiencias de los estudiantes sobre esta modalidad deben provocar la reflexión de las comunidades educativas de las IES públicas, no sólo por la diversidad de condiciones de los estudiantes, sino también de los efectos económicos y emocionales del confinamiento, para flexibilizar el currículo, mencionan los expertos como Chehaibar (2020), también para pensar en el uso de las plataformas en función de las necesidades de cada asignatura, no podemos homogeneizar las clases virtuales, porque las dinámicas y objetivos de los cursos son distintos. Esto significa, reemplazar la idea de que mientras más plataformas se usen en una clase, será mejor; sino que hay que empezar a pensar ¿cómo aprovechar mejor los recursos digitales, para los fines educativos de cada objetivo de asignatura?

Asimismo, para que haya pertinencia, la educación tiene que ser flexible y adaptarse a las necesidades y características de los estudiantes y de los diversos contextos sociales y culturales. Esto exige, transitar desde una pedagogía de la homogeneidad hacia una pedagogía 
de la diversidad, o como dice Gunther Dietz (2020, 2021) transitar de un modelo de universidad a uno de pluriversidad, aprovechando ésta como una oportunidad para enriquecer los procesos de enseñanza, aprendizaje y optimizar el desarrollo personal y social.

La pandemia del virus aceleró la incorporación de los recursos digitales en los procesos educativos, ahora es importante que en las IES públicas no se postergue más esta modalidad educativa en la que llevan ventaja las IES privadas. La identificación de necesidades puede servir como guía para fortalecer la formación docente, legitimar la presencia y dominio de conocimientos de los docentes, además de diseñar estrategias para los estudiantes que no cuentan con disponibilidad de equipos, internet en casa y manejo de plataformas.

Es preciso mantener la reflexión constante de los vínculos entre educación y el ámbito económico, social, para intercambiar propuestas en educación superior sobre formas de romper la homogeneidad de la educación digital y poder pensar realmente desde la diversidad, pero también desde la desigualdad, sobre todo en países como México. Estas experiencias también son una oportunidad para ampliar los análisis sobre los efectos del tiempo que los estudiantes pasan en el mismo lugar, frente al monitor y pensar en estrategias para anclar y mantener el interés del estudiante.

Los casos de estudiantes que han aprendido a ser autodidactas, a organizar el tiempo y a responsabilizarse de su propio conocimiento, no deben ser el foco de interés de las próximas reflexiones, sino de aquellos casos afectados por la desigualdad, la falta de interés y los que no cuentan con habilidades digitales, porque estas condiciones representan una limitación para el aprovechamiento de la educación digital.

Aunque también es importante aprovechar las ventajas del tránsito acelerado a la educación virtual en las universidades públicas, porque desde hace décadas el acceso diferenciado marcó una distancia entre las IES públicas y privadas. Sin embargo, hay grandes obstáculos que se han identificado para llevar este plan a cabo: la falta de conectividad y herramientas, así como el desconocimiento digital, tanto de profesores como de estudiantes. 


\section{Referencias}

Alcántara Santuario, A. (2020). Educación superior y COVID-19: una perspectiva comparada. En Educación y pandemia, una visión académica. México: Instituto de Investigaciones sobre la Universidad y la Educación IISUE. Pp.75-82.

Barrón Tirado, M. C. (2020). La educación en línea. Transiciones y disrupciones. En Educación y pandemia, una visión académica. México: Instituto de Investigaciones sobre la Universidad y la Educación IISUE. Pp. 66-74.

BID (2020). La educación superior en tiempo de COVID-19. Washington: Banco Interamericano de Desarrollo.

Chehaibar, L. M. (2020). Flexibilidad curricular. Tensiones en tiempos de pandemia. En Educación y pandemia, una visión académica. México: Instituto de Investigaciones sobre la Universidad y la Educación IISUE. Pp. 83-91.

De la Cruz Flores, G. (2020). El hogar y la escuela: lógicas en tensión ante la COVID-19. En Educación y pandemia, una visión académica. México: Instituto de Investigaciones sobre la Universidad y la Educación IISUE. Pp. 39-.46.

Dietz, G. (2021). Metodologías colaborativas como apuestas decolonizadoras en Universidades Interculturales.

En: https://www.facebook.com/AndresAugustoArias/videos/10219167544884411

Dietz, G. (2020). Conferencia del Doctor Gunther Dietz - La necesidad de educación intercultural y bilingüe. En: https://www.youtube.com/watch?v=dVdTYBJWEdE\&fbclid=IwAR3bsr-

MLBuvBtzt3E9CkTnOc5owrnHmQeWElaCgvBQB-_kiBJKvm_be6a8

Dietz, G. y Mateos Cortés, L. S. (2020). La interculturalidad educativa en tiempos de pandemia. Muchas sombras y algunas luces. En Educar en la diversidad, La educación intercultural frente a la pandemia (1) No. 1. Argentina: Consejo Latinoamericano de Ciencias Sociales (CLACSO). Pp. 34-42.

Didou, S. (2002). Transnacionalización de la educación superior, aseguramiento de la calidad y acreditación en México. En: http://www.iesalc.edu.org

Díaz Barriga, Á. (2020). La escuela ausente, la necesidad de replantear su significado. En Educación y pandemia, una visión académica. México: Instituto de Investigaciones sobre la Universidad y la Educación IISUE. Pp. 19-29. 
Ducoing Watty, P. (2020). Una expresión de la desigualdad en educación básica durante la emergencia sanitaria. En Educación y pandemia, una visión académica. México: Instituto de Investigaciones sobre la Universidad y la Educación IISUE. Pp. 55-64.

Ibero, (2020). COVID-19: Educación en línea va más allá de dar clases por videoconferencia, En: https://ibero.mx/prensa/covid-19-educacion-en-linea-va-mas-alla-de-dar-clases-porvideoconferencia

López Ramírez, M.; S. A. Rodríguez, (2020). Trayectorias escolares en la educación superior ante la pandemia ¿continuar, interrumpir o desistir?, En Educación y pandemia, una visión académica. México: Instituto de Investigaciones sobre la Universidad y la Educación IISUE. Pp. 103-113.

Plá, S. (2000). La pandemia en la escuela: entre la opresión y la esperanza. En Educación y pandemia, una visión académica. México: Instituto de Investigaciones sobre la Universidad y la Educación IISUE. Pp. 30-39.

http://dialogossobreeducacion.cucsh.udg.mx/index.php/DSE/about/submissions\#authorGuide lines

Torres Santomé, J. (2020). Seminario Jurjo Torres Santomé, Creación de mentalidades neoliberales $y$ neoconservadoras (Conferencia). En: https://www.youtube.com/watch?v=rHxryeolHeA\&feature=share\&fbclid=IwAR3kiV9VYw 8JoJ01LC0OZG_vtx8VGCKfZBC_25FYY-M6eGr8DPAOfxn8oUc UNESCO e IESALC (2020). Análisis de impactos, respuestas políticas y recomendaciones. En: http://www.iesalc.unesco.org/wp-content/uploads/2020/05/COVID-19-ES-130520.pdf (23 de 2020) 